\title{
Review Article \\ Sympathoexcitation Associated with Renin-Angiotensin System in Metabolic Syndrome
}

\author{
Takuya Kishi ${ }^{1}$ and Yoshitaka Hirooka ${ }^{2}$ \\ ${ }^{1}$ Department of Advanced Therapeutics for Cardiovascular Diseases, Kyushu University Graduate School of Medical Sciences, \\ 3-1-1 Maidashi, Higashi-ku, Fukuoka 812-8582, Japan \\ ${ }^{2}$ Department of Advanced Cardiovascular Regulation and Therapeutics, Kyushu University Graduate School of Medical Sciences, \\ 3-1-1 Maidashi, Higashi-ku, Fukuoka 812-8582, Japan
}

Correspondence should be addressed to Yoshitaka Hirooka; hyoshi@cardiol.med.kyushu-u.ac.jp

Received 31 August 2012; Revised 26 December 2012; Accepted 9 January 2013

Academic Editor: B. Waeber

Copyright (C) 2013 T. Kishi and Y. Hirooka. This is an open access article distributed under the Creative Commons Attribution License, which permits unrestricted use, distribution, and reproduction in any medium, provided the original work is properly cited.

\begin{abstract}
Renin-angiotensin system (RAS) is activated in metabolic syndrome (MetS), and RAS inhibitors are preferred for the treatments of hypertension with MetS. Although RAS activation is important for the therapeutic target, underlying sympathetic nervous system (SNS) activation is critically involved and should not be neglected in the pathogenesis of hypertension with MetS. In fact, previous studies have suggested that SNS activation has the interaction with RAS activation and/or insulin resistance. As a novel aspect connecting the importance of SNS and RAS activation, we and other investigators have recently demonstrated that angiotensin II type 1 receptor $\left(\mathrm{AT}_{1} \mathrm{R}\right)$ blockers (ARBs) improve SNS activation in patients with MetS. In the animal studies, SNS activation is regulated by the $\mathrm{AT}_{1} \mathrm{R}$-induced oxidative stress in the brain. We have also demonstrated that orally administered ARBs cause sympathoinhibition independent of the depressor effects in dietary-induced hypertensive rats. Interestingly, these benefits on SNS activation of ARBs in clinical and animal studies are not class effects of ARBs. In conclusion, SNS activation associated with RAS activation in the brain should be the target of the treatment, and ARBs could have the potential benefit on SNS activation in patients with MetS
\end{abstract}

\section{Introduction}

Metabolic syndrome (MetS) is characterized by visceral obesity, impaired fasting glucose, dyslipidemia, and hypertension $[1,2]$. The increasing number of patients with MetS is a worldwide health problem because patients with MetS are considered to be at a high risk for cardiovascular disease. In the pathogenesis of MetS, renin-angiotensin system (RAS) is activated in various organs and tissues [3-6], and RAS inhibitors, such as angiotensin converting enzyme (ACE) inhibitors or angiotensin receptor blockers (ARBs), are preferred for the treatments of hypertension with MetS because of the prominent depressor effect with the improvement of insulin resistance [7-9]. Furthermore, in the pathogenesis of hypertension with MetS, underlying sympathetic nervous system (SNS) activation is critically involved [10-14], and previous studies have suggested that SNS activation has the interaction with insulin resistance [15] and/or RAS activation
$[16,17]$. In the animal studies, SNS activation is regulated by angiotensin-II-type-1-receptor- $\left(\mathrm{AT}_{1} \mathrm{R}\right.$-) induced oxidative stress in the brain [18-23], and recently, we have demonstrated that SNS activation is strongly mediated by $\mathrm{AT}_{1} \mathrm{R}$ induced oxidative stress in the brain of animal models with MetS [24]. As the novel aspect connecting the importance of SNS and RAS activation, in the present paper, we focused on the SNS activation mediated by RAS activation in the brain of MetS.

\section{Sympathetic Overactivation in MetS: Clinical Study}

Insulin resistance and SNS activation have important roles in the pathogenesis of MetS [10, 15, 25-29]. Urinary excretion of catecholamine metabolites becomes elevated and more pronounced as the number of symptoms of MetS increases 
[27]. Sympathetic neural discharge is markedly potentiated [25], leading to increased insulin levels and elevated blood pressure [10]. Elevated levels of muscle sympathetic nerve activity (MSNA) are associated with obesity-induced subclinical organ damage, even in the absence of hypertension [30]. Interestingly, central obesity demonstrates augmented sympathetic outflow when compared to noncentral adiposity body types [27, 31-33] even when hypertension is not present. Furthermore, the presence of hypertension in MetS results in a further augmentation of the SNS activation [25, 33]. It should be noted that activation of the SNS is supposed to decrease the body weight. However, this does not occur in MetS with obese subjects. Recently, this is because of the interruption of the SNS activation as an action of energy expenditure suggested by Grassi [14] who modified the scheme originally made by Landsberg. Although it is difficult to prove this action in humans, activation of the brown adipose tissue, which increases energy expenditure, does not occur in obese subjects despite the fact that renal and lumbar SNS activation occur [34].

The accumulation of body fat with a positive energy balance was first shown in animal models to result in SNS activation $[35,36]$. The chronic increase in basal SNS activation is presumably aimed at stimulating $\beta$-adrenergic thermogenesis to prevent further fat storage [37] but can also stimulate lipolysis to increase nonesterified free fatty acids, contributing to insulin resistance. Adipose tissue itself can act as an endocrine organ and express various adipokines, which may directly or indirectly activate SNS [29]. A chronically elevated SNS activation could in turn impair $\beta$-adrenergic signaling, reduce stimulation of metabolism, and contribute to obesity and insulin resistance [10, 29]. Moreover, evidence demonstrates that insulin release increases MSNA and enhances the arterial baroreflex gain of SNS activation [38]. Furthermore, SNS activation is important for the occurrence and progression of hypertension leading to hypertensive organ damage in MetS [15]. Thus, treatments targeting the SNS activation are reasonable for patients with MetS.

\section{Sympathetic Overactivation in Animal Models with MetS}

It has been well documented that insulin can augment sympathetic outflow in animals via intracerebroventricular administration $[39,40]$. Sympathetic outflow increases upon the injection of insulin into the third cerebral ventricle of rats [39]. A recent study also has demonstrated that the insulin affects arcuate nucleus, via the paraventricular nucleus of the hypothalamus, to increase the SNS activation and increase baroreflex gain of SNS activation [41]. While very little insulin is produced in the central nervous system, central insulin receptors are found on the hypothalamus [42] and can cause a coactivation of the SNS activation through transport-mediated uptake across the blood-brain barrier of peripherally secreted insulin [29]. In addition, the arcuate nucleus is unusual in that it contains highly permeable capillaries [43], such that insulin may directly activate receptors in this area without a specific transport mechanism [44].
These results suggest that the increase in plasma insulin causes sympathoexcitation via central mechanisms in animal models with MetS. As other mechanisms, we should discuss about leptin. Leptin is an adipocyte-derived hormone that has a key role in the regulation of the body weight through its actions on appetite and metabolism in addition to increasing blood pressure and SNS activation [40]. Rahmouni et al. suggested that mice with diet-induced obesity exhibit circulating hyperleptinemia and resistance to the metabolic actions of leptin. Recently, it was also demonstrated that RAS in the brain selectively facilitates renal and brown adipose tissue sympathetic nerve responses to leptin while sparing effects on food intake [45] and that hypothalamic arcuate nucleus plays an important role in mediating the sympathetic nerve responses to leptin and in the adverse sympathoexcitatory effects of leptin in obesity [46].

In the other possible central mechanisms of sympathoexcitation in MetS, oxidative stress in the brain would be considered to play a pivotal role. Oxidative stress in the hypothalamus contributes to the progression of obesityinduced hypertension through central sympathoexcitation [47]. We also have demonstrated that $\mathrm{AT}_{1} \mathrm{R}$-induced oxidative stress in the rostral ventrolateral medulla (RVLM) induces sympathoexcitation in rats with obesity-induced hypertension [24, 48]. RVLM is known as a major vasomotor center in the brainstem, and SNS activation is mediated by neuronal activity in the RVLM $[49,50]$. In the RVLM, $\mathrm{AT}_{1} \mathrm{R}$ induced oxidative stress has been determined to be a major sympathoexcitatory [21-23, 51]. Neurons in the RVLM contribute to elevated sympathetic outflow in rats with dietaryinduced obesity [52]. In obesity-induced hypertension, systemic oxidative stress is increased and is associated with the development and progression of hypertension in various organs [53-56]. Taken together, it could be considered that SNS activation is increased in animal models with MetS via $\mathrm{AT}_{1} \mathrm{R}$ and oxidative stress in the brain.

\section{Renin-Angiotensin System Activation in MetS}

Previous many studies have demonstrated that RAS is activated in various organs and tissues in MetS [3-6, 29, 57]. Several peptides involved in the RAS have been implicated in insulin resistance [58-60] or hypertension [61, 62]. Hypercholesterolemia can increase $\mathrm{AT}_{1} \mathrm{R}$ gene expression on vascular smooth muscle cells $[63,64]$. Low-density lipoprotein receptor-deficient mice fed a diet enriched in fat and cholesterol exhibited elevated plasma concentrations of angiotensinogen, angiotensin II [65], and brain angiotensinogen [66]. These results indicate that hypercholesterolemia stimulates the expression of several components of the RAS.

Prolonged hyperglycemia and hyperinsulinemia could upregulate RAS [67-70]. Furthermore, angiotensin II can reduce whole body glucose utilization and insulin sensitivity, increase skeletal muscle and adipose tissue insulin resistance, and impair insulin signaling and action. Recent studies suggest that the RAS activation influences glucose homeostasis independent of its ability to regulate blood flow. 


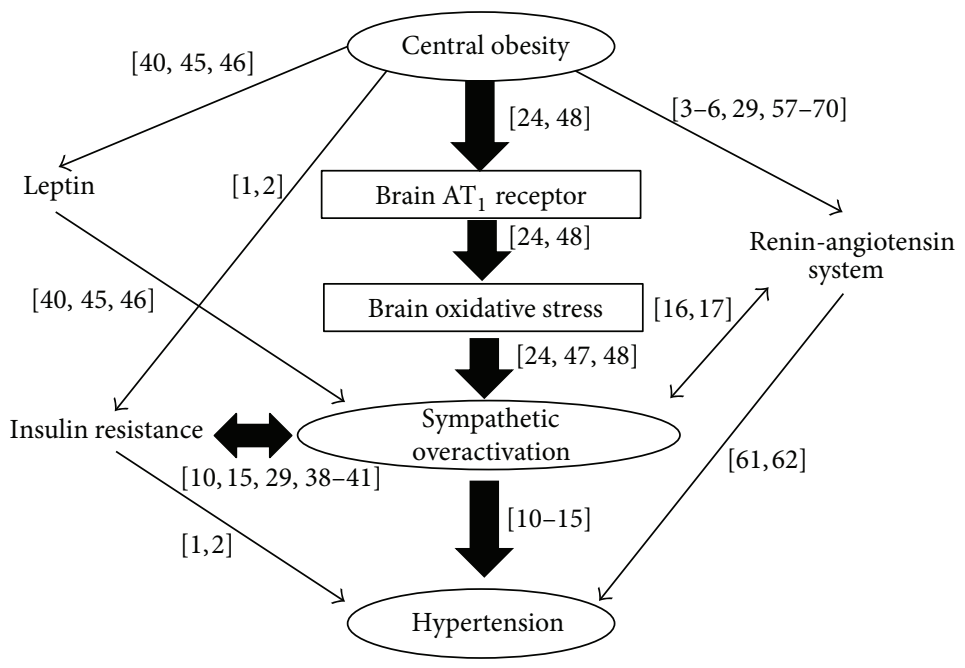

FIGURE 1: A schema presenting our concept in the regulation of sympathetic nervous system mediated by brain renin-angiotensin system in the metabolic syndrome. The numbers on the different arrows are the references from the bibliography.

Angiotensin II infusion into the interstitial space of skeletal muscle in dogs could result in insulin resistance independent of changes in blood flow [71]. Chronic angiotensin II infusion into insulin-sensitive rats was shown to reduce peripheral glucose use and insulin-induced glucose uptake [72]. In a model of angiotensin-II-induced hypertension, significant reduction in tyrosine phosphorylation of the insulin receptor and the insulin receptor substrate 1 in skeletal muscle was consistent with a whole-body reduction in insulin-mediated glucose transport [73]. Furthermore, RAS inhibitors could ameliorate insulin resistance [74, 75]. These studies could strongly suggest that RAS activation may contribute to insulin resistance in the MetS. Additionally, several largescale clinical trials have demonstrated that the use of ARBs or ACE inhibitors can significantly reduce the incidence of new-onset diabetes in hypertensive patients and/or patients with MetS [76-79].

\section{Renin-Angiotensin-System-Induced Sympathetic Overactivation in MetS}

Both SNS and RAS are activated in obesity, and both systems can upregulate the action of the other $[16,17]$. RAS is not only implicated in the observed sympathetic overdrive in obesity but may also provide a mechanism through which sympathetic overactivation leads to chronic hypertension [29]. In a previous clinical study, the inhibition of angiotensin II for three months in patients with MetS reduced MSNA activity by $21 \%$ [80].

With regard to the central SNS regulation, sympathetic outflow is strongly mediated by RAS activation in the brain. It has already been demonstrated that RAS in the brain mediates SNS activation via oxidative stress in animal models with hypertension and/or heart failure [18-23]. In rats with obesity-induced hypertension, $\mathrm{AT}_{1} \mathrm{R}$-induced oxidative stress in the RVLM induces sympathoexcitation $[24,48]$. Taken together, it could be considered that SNS activation could be mediated by RAS activation and oxidative stress in the brain of MetS.

\section{Angiotensin II Receptor Blockers Cause Sympathoinhibition in MetS}

In hypertensive patients with MetS, RAS inhibitors such as ACE inhibitors or ARBs are preferred [7-9]. In our recent study, we have found several new findings as follows: (1) telmisartan, but not candesartan, reduced plasma norepinephrine concentrations in the patients with MetS in spite of the similar depressor effects; (2) amelioration of baroreflex dysfunction in patients with MetS was significantly greater in the telmisartan-treated group than in the candesartan-treated group [28]. Our findings provide novel insight indicating that ARBs have beneficial effects on autonomic function in patients with MetS. Moreover, sympathoinhibitory effect of ARBs might not be a class effect. We also previously demonstrated that telmisartan inhibits SNS activation in hypertensive rats $[22,23]$. In the animal studies, direct microinjection of ARBs into the RVLM or intracerebroventricular infusion of ARBs inhibits SNS activation in hypertensive rats [21, 8183]. Interestingly, a previous study found that telmisartan can penetrate the blood-brain barrier in both a dose- and time-dependent manner to inhibit the centrally mediated effects of angiotensin II following peripheral administration [84]. We demonstrated that oxidative stress in the RVLM causes sympathoexcitation and baroreflex dysfunction [23, 51]. Taken together, these findings lead us to speculate that orally administered telmisartan, but not candesartan, could cause sympathoinhibition due to a reduction in the oxidative stress in the brain. Although other ARBs also inhibit the central actions of angiotensin II in the brain [84-89], these effects might differ depending on the pharmacokinetics and properties of each drug [84]. For example, in terms of agonist activity of peroxisome proliferator-activated-receptor(PPAR-) gamma, a previous study suggested that orally 
administered rosiglitazone, PPAR-gamma agonist, promotes a central antihypertensive effect via upregulation of PPARgamma and alleviation of oxidative stress in the RVLM of spontaneously hypertensive rats [90]. Although both of telmisartan and candesartan have the function as a partial agonist of PPAR-gamma, only telmisartan can achieve this effect with therapeutics doses [91], and telmisartan might have benefits associated with agonistic effect of PPAR-gamma to a greater extent than candesartan $[87,88]$. Further studies are necessary to clarify whether the ARBs-induced sympathoinhibitory effect is dependent on the central PPARgamma in MetS or not.

\section{Summary}

RAS and SNS are abnormally activated in MetS, and there are interactions between RAS, insulin resistance, and SNS activation. Among these interactions, SNS activation is mainly augmented by RAS activation and oxidative stress in the brain (Figure 1). In patients with MetS, SNS activation mediated by RAS activation and oxidative stress in the brain should be the target of the treatments for hypertension, and ARBs could have the potential benefit on SNS activation.

\section{References}

[1] S. M. Grundy, J. I. Cleeman, S. R. Daniels et al., "Diagnosis and management of the metabolic syndrome: an American Heart Association/National Heart, Lung, and Blood Institute scientific statement," Circulation, vol. 112, no. 17, pp. 2735-2752, 2005.

[2] S. M. Grundy, "Metabolic syndrome pandemic," Arteriosclerosis, Thrombosis, and Vascular Biology, vol. 28, pp. 629-636, 2008.

[3] R. Sarzani, F. Salvi, P. Dessì-Fulgheri, and A. Rappelli, "Reninangiotensin system, natriuretic peptides, obesity, metabolic syndrome, and hypertension: an integrated view in humans," Journal of Hypertension, vol. 26, no. 5, pp. 831-843, 2008.

[4] A. D. de Kloet, E. G. Krause, and S. C. Woods, "The renin angiotensin system and the metabolic syndrome," Physiology and Behavior, vol. 100, no. 5, pp. 525-534, 2010.

[5] K. Putnam, R. Shoemaker, F. Yiannikouris, and L. A. Cassia, "The renin-angiotensin system: a target of and contributor to dyslipidemias, altered glucose homeostasis, and hypertension of the metabolic syndrome," American Journal of Physiology, vol. 302, pp. H1219-H1230, 2012.

[6] N. S. Kalupahana and N. Moustaid-Moussa, "The reninangiotensin system: a link between obesity, inflammation and insulin resistance," Obesity Reviews, vol. 13, pp. 136-149, 2012.

[7] W. J. Elliott and P. M. Meyer, "Incident diabetes in clinical trials of antihypertensive drugs: a network meta-analysis," The Lancet, vol. 369, no. 9557, pp. 201-207, 2007.

[8] Y. Kamari, A. Harari, A. Shaish et al., "Effect of telmisartan, angiotensin II receptor antagonist, on metabolic profile in fructose-induced hypertensive, hyperinsulinemic, hyperlipidemic rats," Hypertension Research, vol. 31, no. 1, pp. 135-140, 2008.

[9] T. Ogihara, K. Kikuchi, H. Matsuoka et al., "The Japanese Society of Hypertension Guidelines for the Management of Hypertension (JSH, 2009)," Hypertension Research, vol. 32, pp. 3-107, 2009.
[10] L. Landsberg, "Insulin-mediated sympathetic stimulation: role in the pathogenesis of obesity-related hypertension (or, how insulin affects blood pressure, and why)," Journal of Hypertension, vol. 19, no. 3, pp. 523-528, 2001.

[11] K. Raumouni, M. L. Correla, W. G. Haynes, and A. L. Mark, "Obesity associated hypertension: new insights into mechanisms," Hypertension, vol. 45, pp. 9-14, 2005.

[12] M. Esler, N. Straznicky, N. Eikelis, K. Masuo, G. Lambert, and E. Lambert, "Mechanisms of sympathetic activation in obesityrelated hypertension," Hypertension, vol. 48, no. 5, pp. 787-796, 2006.

[13] G. Grassi, "Sympathetic overdrive and cardiovascular risk in the metabolic syndrome," Hypertension Research, vol. 29, no. 11, pp. 839-847, 2006

[14] G. Grassi, "Adrenergic overdrive as the link among hypertension, obesity, and impaired thermogenesis: lights and shadows," Hypertension, vol. 49, no. 1, pp. 5-6, 2007.

[15] G. Grassi, F. Arenare, F. Quarti-Trevano, G. Seravalle, and G. Mancia, "Heart rate, sympathetic cardiovascular influences, and the metabolic syndrome," Progress in Cardiovascular Diseases, vol. 52, no. 1, pp. 31-37, 2009.

[16] T. Matsukawa, E. Gotoh, K. Minamisawa et al., "Effects of intravenous infusions of angiotensin II on muscle sympathetic nerve activity in humans," American Journal of Physiology, vol. 261, no. 3, pp. R690-R696, 1991.

[17] T. Zera, M. Ufnal, and E. Szczepanska-Sadowska, "Central TNF$\alpha$ elevates blood pressure and sensitizes to central pressor action of angiotensin II in the infarcted rats," The Journal of Physiology and Pharmacology, vol. 59, no. 8, pp. 117-121, 2008.

[18] M. C. Zimmerman, E. Lazartigues, J. A. Lang et al., "Superoxide mediates the actions of angiotensin II in the central nervous system," Circulation Research, vol. 91, no. 11, pp. 1038-1045, 2002.

[19] M. C. Zimmerman, E. Lazartigues, R. V. Sharma, and R. L. Davisson, "Hypertension caused by angiotensin II infusion involves increased superoxide production in the central nervous system," Circulation Research, vol. 95, no. 2, pp. 210-216, 2004.

[20] M. Nozoe, Y. Hirooka, Y. Koga et al., "Mitochondria-derived reactive oxygen species mediate sympathoexcitation induced by angiotensin II in the rostral ventrolateral medulla," Journal of Hypertension, vol. 26, no. 11, pp. 2176-2184, 2008.

[21] T. Kishi, Y. Hirooka, S. Konno, K. Ogawa, and K. Sunagawa, "Angiotensin II type 1 receptor-activated caspase3 through ras/mitogen-activated protein kinase/extracellular signal-regulated kinase in the rostral ventrolateral medulla is involved in sympathoexcitation in stroke-prone spontaneously hypertensive rats," Hypertension, vol. 55, no. 2, pp. 291-297, 2010.

[22] Y. Hirooka, Y. Sagara, T. Kishi, and K. Sunagawa, "Oxidative stress and central cardiovascular regulation-pathogenesis of hypertension and therapeutic aspects," Circulation Journal, vol. 74, no. 5, pp. 827-835, 2010.

[23] T. Kishi, Y. Hirooka, and K. Sunagawa, "Sympathoinhibition caused by orally administered telmisartan through blockade of AT1 receptor in rostral ventrolateral medulla of hypertensive rats," Hypertension Research, vol. 35, pp. 940-946, 2012.

[24] S. Konno, Y. Hirooka, T. Kishi, and K. Sunagawa, "Sympathoinhibitory effects of telmisartan through the reduction of oxidative stress in the rostral ventrolateral medulla of obesityinduced hypertensive rats," Journal of Hypertension, vol. 30, pp. 1992-1999, 2012. 
[25] G. Grassi, R. Dell'Oro, F. Quarti-Trevano et al., "Neuroadrenergic andreflex abnormalities in patients with metabolic syndrome," Diabetologia, vol. 48, pp. 1359-1365, 2005.

[26] G. Mancia, P. Bousquet, J. L. Elghozi et al., "The sympathetic nervous system and the metabolic syndrome," Journal of Hypertension, vol. 25, no. 5, pp. 909-920, 2007.

[27] Z. S. K. Lee, J. A. J. H. Critchley, B. Tomlinson et al., "Urinary epinephrine and norepinephrine interrelations with obesity, insulin, and the metabolic syndrome in Hong Kong Chinese," Metabolism, vol. 50, no. 2, pp. 135-143, 2001.

[28] T. Kishi, Y. Hirooka, S. Konno, and K. Sunagawa, "Angiotensin II receptor blockers improve endothelial dysfunction associated with sympathetic hyperactivity in metabolic syndrome," Journal of Hypertension, vol. 30, pp. 1646-1655, 2012.

[29] M. M. Smith and C. T. Minson, "Obesity and adipokines: effect on sympathetic overactivity," The Journal of Physiology, vol. 590, pp. 1787-1801, 2012.

[30] E. Lambert, C. I. Sari, T. Dawood et al., "Sympathetic nervous system activity is associated with obesity-induced subclinical organ damage in young adults," Hypertension, vol. 56, no. 3, pp. 351-358, 2010.

[31] M. S. Rumantir, M. Vaz, G. L. Jennings et al., "Neural mechanisms in human obesity-related hypertension," Journal of Hypertension, vol. 17, pp. 1125-1133, 1999.

[32] G. E. Alvarez, T. P. Ballard, S. D. Beske, and K. P. Davy, "Subcutaneous obesity is not associated with sympathetic neural activation," American Journal of Physiology, vol. 287, no. 1, pp. H414-H418, 2004.

[33] R. J. Huggett, J. Burns, A. F. Mackintosh, and D. A. Mary, “Sympathetic neural activation in nondiabetic metabolic syndrome and its further augmentation by hypertension," Hypertension, vol. 44, no. 6, pp. 847-852, 2004.

[34] W. I. Sivitz, S. M. Wayson, M. L. Bayless, C. A. Sinkey, and W. G. Haynes, "Obesity impairs vascular relaxation in human subjects: hyperglycemia exaggerates adrenergic vasoconstriction. Arterial dysfunction in obesity and diabetes," Journal of Diabetes and Its Complications, vol. 21, no. 3, pp. 149-157, 2007.

[35] L. Landsberg, "Insulin resistance, energy balance andsympathetic nervous system activity," Clinical and Experimental Hypertension, vol. 12, pp. 817-830, 1990.

[36] L. Landsberg and J. B. Young, "Sympathoadrenal activity andobesity: physiological rationale for the use of adrenergicthermogenic drugs," International Journal of Obesity and Related Metabolic Disorders, vol. 17, supplement 1, pp. S29-S34, 1993.

[37] A. G. Dulloo, "A sympathetic defense against obesity," Science, vol. 297 , no. 5582 , pp. $780-781,2002$.

[38] C. N. Young, S. H. Deo, K. Chaudhary, J. P. Thyfault, and P. J. Fadel, "Insulin enhances the gain of arterial baroreflex control of muscle sympathetic nerve activity in humans," The Journal of Physiology, vol. 588, no. 18, pp. 3593-3603, 2010.

[39] M. S. Muntzel, D. A. Morgan, A. L. Mark, and A. K. Johnson, "Intracerebroventricular insulin produces nonuniform regional increases in sympathetic nerve activity," American Journal of Physiology, vol. 267, no. 5, pp. R1350-R1355, 1994.

[40] K. Rahmouni, D. A. Morgan, G. M. Morgan et al., "Hypothalamic PI3K and MAPK differentially mediate regional sympathetic activation to insulin," The Journal of Clinical Investigation, vol. 114, no. 5, pp. 652-658, 2004.
[41] P. A. Cassaglia, S. M. Hermes, S. A. Aicher, and V. L. Brooks, "Insulin acts in the arcuate nucleus to increase lumbar sympathetic nerve activity and baroreflex function in rats," The Journal of Physiology, vol. 589, no. 7, pp. 1643-1662, 2011.

[42] D. F. Hopkins and G. Williams, "Insulin receptors arewidely distributed in human brain and bind human andporcine insulin with equal affinity," Diabetic Medicine, vol. 14, pp. 1044-1050, 1997.

[43] P. Ciofi, "The arcuate nucleus as a circumventricular organ in the mouse," Neuroscience Letters, vol. 487, no. 2, pp. 187-190, 2011.

[44] R. A. Dampney, “Arcuate nucleus—a gateway for insulin'saction on sympathetic activity," The Journal of Physiology, vol. 589, pp. 2109-2110, 2011.

[45] A. M. Hilzendeger, D. A. Morgan, L. Brooks et al., "A brain leptin-renin angiotensin system interaction in the regulation of sympathetic nerve activity," American Journal of Physiology, vol. 303, pp. H197-H206, 2012.

[46] S. M. Harlan, D. A. Morgan, K. Agassandian et al., "Ablation of the leptin receptor in the hypothalamic arcuate nucleus abrogates leptin-induced sympathetic activation," Circulation Research, vol. 108, no. 7, pp. 808-812, 2011.

[47] A. Nagae, M. Fujita, H. Kawarazaki, H. Matsui, K. Ando, and T. Fujita, "Sympathoexcitation by oxidative stress in the brain mediates arterial pressure elevation in obesity-induced hypertension," Circulation, vol. 119, no. 7, pp. 978-986, 2009.

[48] T. Kishi, Y. Hirooka, K. Ogawa, S. Konno, and K. Sunagawa, "Calorie restriction inhibits sympathetic nerve activity via antioxidant effect in the rostral ventrolateral medulla of obesityinduced hypertensive rats," Clinical and Experimental Hypertension, vol. 33, no. 4, pp. 240-245, 2011.

[49] R. A. L. Dampney, "Functional organization of central pathways regulating the cardiovascular system," Physiological Reviews, vol. 74, no. 2, pp. 323-364, 1994.

[50] P. G. Guyenet, "The sympathetic control of blood pressure," Nature Reviews Neuroscience, vol. 7, no. 5, pp. 335-346, 2006.

[51] T. Kishi, Y. Hirooka, Y. Kimura, K. Ito, H. Shimokawa, and A. Takeshita, "Increased reactive oxygen species in rostral ventrolateral medulla contribute to neural mechanisms of hypertension in stroke-prone spontaneously hypertensive rats," Circulation, vol. 109, no. 19, pp. 2357-2362, 2004.

[52] S. D. Stocker, R. Meador, and J. M. Adams, "Neurons of the rostral ventrolateral medulla contribute to obesity-induced hypertension in rats," Hypertension, vol. 49, no. 3, pp. 640-646, 2007.

[53] A. D. Dobrian, M. J. Davies, S. D. Schriver, T. J. Lauterio, and R. L. Prewitt, "Oxidative stress in a rat model of obesity-induced hypertension," Hypertension, vol. 37, no. 2, pp. 554-560, 2001.

[54] A. D. Smith, M. W. Brands, M. H. Wang, and A. M. Dorrance, "Obesity-induced hypertension develops in young rats independently of the renin-angiotensin-aldosterone system," Experimental Biology and Medicine, vol. 231, no. 3, pp. 282-287, 2006.

[55] P. Dandona, A. Aljada, A. Chaudhuri, P. Mohanty, and R. Garg, "Metabolic syndrome: a comprehensive perspective based on interactions between obesity, diabetes, and inflammation," Circulation, vol. 111, no. 11, pp. 1448-1454, 2005.

[56] X. Zhang, F. Dong, J. Ren, M. J. Driscoll, and B. Culver, "High dietary fat induces NADPH oxidase-associated oxidative stress and inflammation in rat cerebral cortex," Experimental Neurology, vol. 191, no. 2, pp. 318-325, 2005. 
[57] C. M. Boustany, K. Bharadwaj, A. Daugherty, D. R. Brown, D. C. Randall, and L. A. Cassis, "Activation of the systemic and adipose renin-angiotensin system in rats with diet-induced obesity and hypertension," American Journal of Physiology, vol. 287, no. 4, pp. R943-R949, 2004.

[58] J. F. Giani, M. A. Mayer, M. C. Muñoz et al., "Chronic infusion of angiotensin-(1-7) improves insulin resistance and hypertension induced by a high-fructose diet in rats," American Journal of Physiology, vol. 296, no. 2, pp. E262-E271, 2009.

[59] S. H. Santos, J. F. Braga, E. G. Mario et al., "Improved lipid and glucose metabolism in transgenic rats with increased circulating angiotensin-(1-7)," Arteriosclerosis, Thrombosis, and Vascular Biology, vol. 30, pp. 953-961, 2010.

[60] C. Liu, X. H. Lv, H. X. Li et al., "Angiotensin-(1-7) suppresses oxidative stress and improves glucose uptake via Max receptor in adipocytes," Acta Diabetologica, vol. 49, pp. 291-299, 2011.

[61] S. H. Padia, B. A. Kemp, N. L. Howell, J. J. Gildea, S. R. Keller, and R. M. Carey, "Intrarenal angiotensin III infusion induces natriuresis and angiotensin type 2 receptor translocation in Wistar-Kyoto but not in spontaneously hypertensive rats," Hypertension, vol. 53, no. 2, pp. 338-343, 2009.

[62] E. A. Bourassa, X. Fang, X. Li, A. F. Sved, and R. C. Speth, "AT1 angiotensin II receptor and novel non-AT1, non-AT2 angiotensin II/III binding site in brainstem cardiovascular regulatory centers of the spontaneously hypertensive rat," Brain Research, vol. 1359, pp. 98-106, 2010.

[63] G. Nickenig, A. Sachinidis, F. Michaelsen, M. Böhm, S. Seewald, and H. Vetter, "Upregulation of vascular angiotensin II receptor gene expression by low- density lipoprotein in vascular smooth muscle cells," Circulation, vol. 95, no. 2, pp. 473-478, 1997.

[64] G. Nickenig, O. Jung, K. Strehlow et al., "Hypercholesterolemia is associated with enhanced angiotensin AT1- receptor expression," American Journal of Physiology, vol. 272, no. 6, pp. H2701H2707, 1997.

[65] A. Daugherty, D. L. Rateri, H. Lu, T. Inagami, and L. A. Cassis, "Hypercholesterolemia stimulates angiotensin peptide synthesis and contributes to atherosclerosis through the AT1A receptor," Circulation, vol. 110, no. 25, pp. 3849-3857, 2004.

[66] L. Mateos, M. A. M. Ismail, F. J. Gil-Bea et al., "Side chainoxidized oxysterols regulate the brain renin-angiotensin system through a liver X receptor-dependent mechanism," The Journal of Biological Chemistry, vol. 286, no. 29, pp. 25574-25585, 2011.

[67] S. L. Zhang, J. G. Filep, T. C. Hohman, S. S. Tang, J. R. Ingelfinger, and J. S. D. Chan, "Molecular mechanisms of glucose action on angiotensinogen gene expression in rat proximal tubular cells," Kidney International, vol. 55, no. 2, pp. 454-464, 1999.

[68] H. M. Siragy and J. Huang, "Renal (pro)renin receptor upregulation in diabetic rats through enhanced angiotensin AT1 receptor and NADPH oxidase activity," Experimental Physiology, vol. 93, no. 5, pp. 709-714, 2008.

[69] I. Toma, J. J. Kang, A. Sipos et al., "Succinate receptor GPR91 provides a direct link between high glucose levels and rennin release in murine and rabbit kidney," The Journal of Clinical Investigation, vol. 118, no. 7, pp. 2526-2534, 2008.

[70] L. Zhou, H. Xue, P. Yuan et al., "Angiotensin AT1 receptor activation mediates high glucose-induced epithelial-mesenchymal transition in renal proximal tubular cells," Clinical and Experimental Pharmacology and Physiology, vol. 37, no. 9, pp. e152e157, 2010.

[71] J. M. Richey, M. Ader, D. Moore, and R. N. Bergman, "Angiotensin II induces insulin resistance independent of changes in interstitial insulin," American Journal of Physiology, vol. 277, no. 5, pp. E920-E926, 1999.

[72] T. Ogihara, T. Asano, K. Ando et al., "Angiotensin II-induced insulin resistance is associated with enhanced insulin signaling," Hypertension, vol. 40, no. 6, pp. 872-879, 2002.

[73] J. A. Sloniger, V. Saengsirisuwan, C. J. Diehl et al., "Defective insulin signaling in skeletal muscle of the hypertensive TG(mREN2)27 rat," American Journal of Physiology, vol. 288, no. 6, pp. E1074-E1081, 2005.

[74] R. Kouyama, T. Suganami, J. Nishida et al., "Attenuation of dietinduced weight gain and adiposity through increased energy expenditure in mice lacking angiotensin II type la receptor," Endocrinology, vol. 146, no. 8, pp. 3481-3489, 2005.

[75] S. Pscherer, U. Heemann, and H. Frank, "Effect of reninangiotensin system blockade on insulin resistance and inflammatory parameters in patients with impaired glucose tolerance," Diabetes Care, vol. 33, no. 4, pp. 914-919, 2010.

[76] S. Yusuf, H. Gerstein, B. Hoogwerf et al., "Ramipril and the development of diabetes," Journal of the American Medical Association, vol. 286, no. 15, pp. 1882-1885, 2001.

[77] J. I. Barzilay, B. R. Davis, J. A. Cutler et al., "Fasting glucose levels and incident diabetes mellitus in older nondiabetic adults randomized to receive 3 different classes of antihypertensive treatment: a report from the Antihypertensive and LipidLowering Treatment to Prevent Heart Attack Trial (ALLHAT)," Archives of Internal Medicine, vol. 166, no. 20, pp. 2191-2201, 2006.

[78] J. Bosch, S. Yusuf, H. C. Gerstein et al., "Effect of ramipril on the incidence of diabetes," The New England Journal of Medicine, vol. 355, pp. 1551-1562, 2006.

[79] J. J. McMurray, R. R. Holman, S. M. Haffner et al., "Effect of valsartan on the incidence of diabetes andcardiovascular events," The New England Journal of Medicine, vol. 362, pp. 14771490, 2010.

[80] G. Grassi, G. Seravalle, R. Dell'Oro et al., "Comparative effects of candesartan and hydrochlorothiazide on blood pressure, insulin sensitivity, and sympathetic drive in obese hypertensive individuals: results of the CROSS study," Journal of Hypertension, vol. 21, no. 9, pp. 1761-1769, 2003.

[81] X. Y. Gao, F. Zhang, Y. Han et al., "AT1 receptor in rostral ventrolateral medulla mediating blunted baroreceptor reflex in spontaneously hypertensive rats," Acta Pharmacologica Sinica, vol. 25, no. 11, pp. 1433-1438, 2004.

[82] Y. Koga, Y. Hirooka, S. Araki, M. Nozoe, T. Kishi, and K. Sunagawa, "High salt intake enhances blood pressure increase during development of hypertension via oxidative stress in rostral ventrolateral medulla of spontaneously hypertensive rats," Hypertension Research, vol. 31, no. 11, pp. 2075-2083, 2008.

[83] S. Ito, K. Komatsu, K. Tsukamoto, K. Kanmatsuse, and A. F. Sved, "Ventrolateral medulla AT1 receptors support blood pressure in hypertensive rats," Hypertension, vol. 40, no. 4, pp. 552-559, 2002.

[84] P. Gohlke, S. Weiss, A. Jansen et al., "AT1 receptor antagonist telmisartan administered peripherally inhibits central responses to angiotensin II in conscious rats," Journal of Pharmacology and Experimental Therapeutics, vol. 298, no. 1, pp. 6270, 2001.

[85] J. M. Wang, J. Tan, and F. H. H. Leenen, "Central nervous system blockade by peripheral administration of AT1 receptor blockers," Journal of Cardiovascular Pharmacology, vol. 41, no. 4, pp. 593-599, 2003. 
[86] Y. Lin, K. Matsumura, S. Kagiyama, M. Fukuhara, K. Fujii, and M. Iida, "Chronic administration of olmesartan attenuates the exaggerated pressor response to glutamate in the rostral ventrolateral medulla of SHR," Brain Research, vol. 1058, no. 1-2, pp. 161-166, 2005.

[87] Y. Lin, T. Tsuchihashi, S. Kagiyama, K. Matsumura, and I. Abe, "The influence of chronic antihypertensive treatment on the central pressor response in SHR," Hypertension Research, vol. 24, no. 2, pp. 173-178, 2001.

[88] T. Tsuchihashi, S. Kagiyama, K. Matsumura, I. Abe, and M. Fujishima, "Effects of chronic oral treatment with imidapril and TCV-116 on the responsiveness to angiotensin II in ventrolateral medulla of SHR," Journal of Hypertension, vol. 17, no. 7, pp. 917922, 1999.

[89] N. Pelisch, N. Hosomi, M. Ueno et al., "Systemic candesartan reduces brain angiotensin II via downregulation of brain reninangiotensin system," Hypertension Research, vol. 33, no. 2, pp. 161-164, 2010.

[90] M. Schupp, J. Janke, R. Clasen, T. Unger, and U. Kintscher, "Angiotensin type 1 receptor blockers induce peroxisome proliferator-activated receptor-gamma activity," Circulation, vol. 109, no. 17, pp. 2054-2057, 2004.

[91] S. C. Benson, H. A. Pershadsingh, C. I. Ho et al., "Identification of telmisartan as a unique angiotensin II receptor antagonist with selective PPARgamma-modulating activity," Hypertension, vol. 43, no. 5, pp. 993-1002, 2004. 


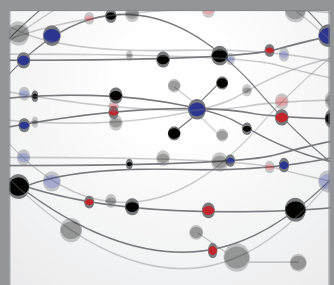

The Scientific World Journal
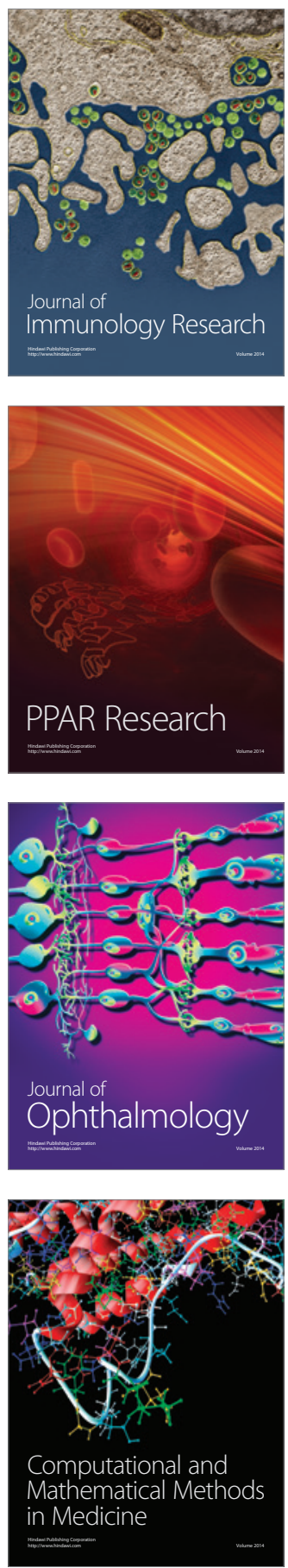

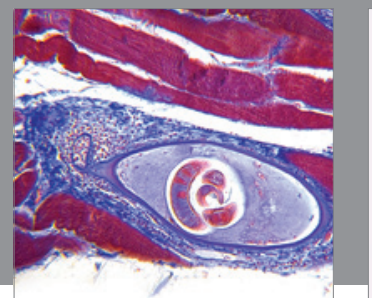

Gastroenterology

Research and Practice
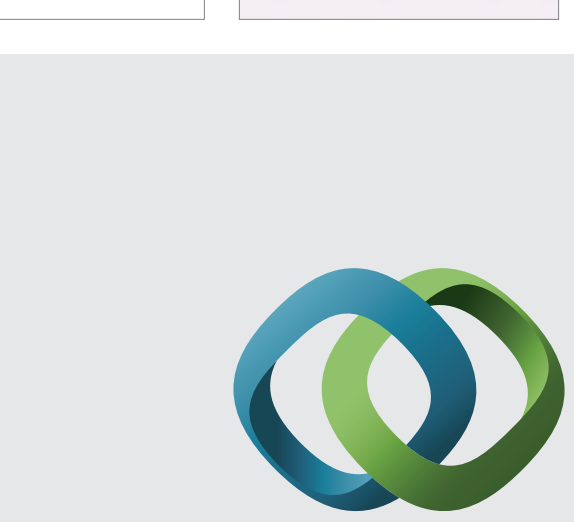

\section{Hindawi}

Submit your manuscripts at

http://www.hindawi.com
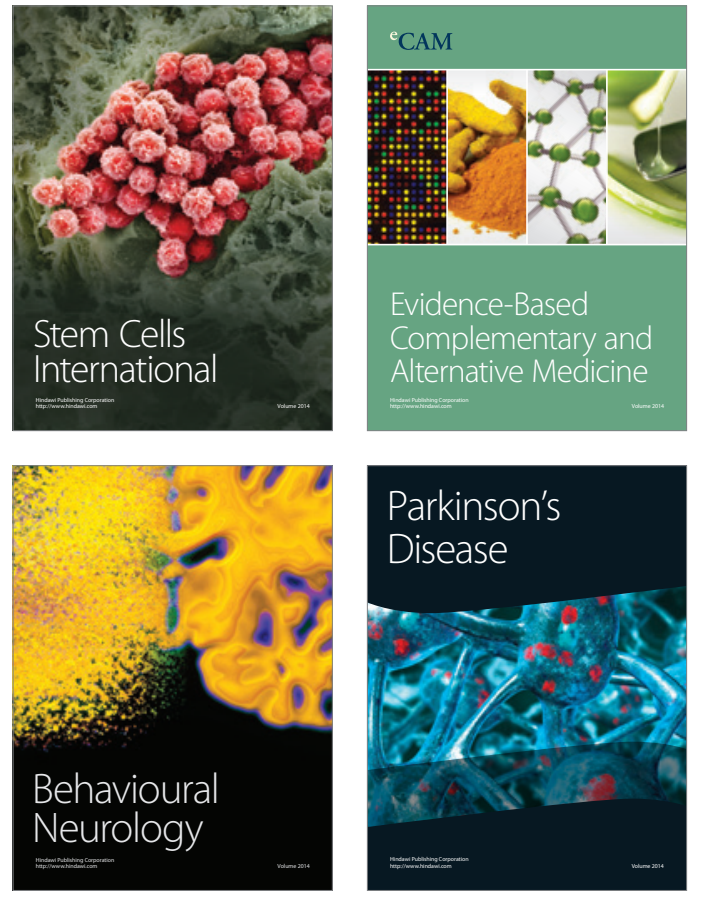
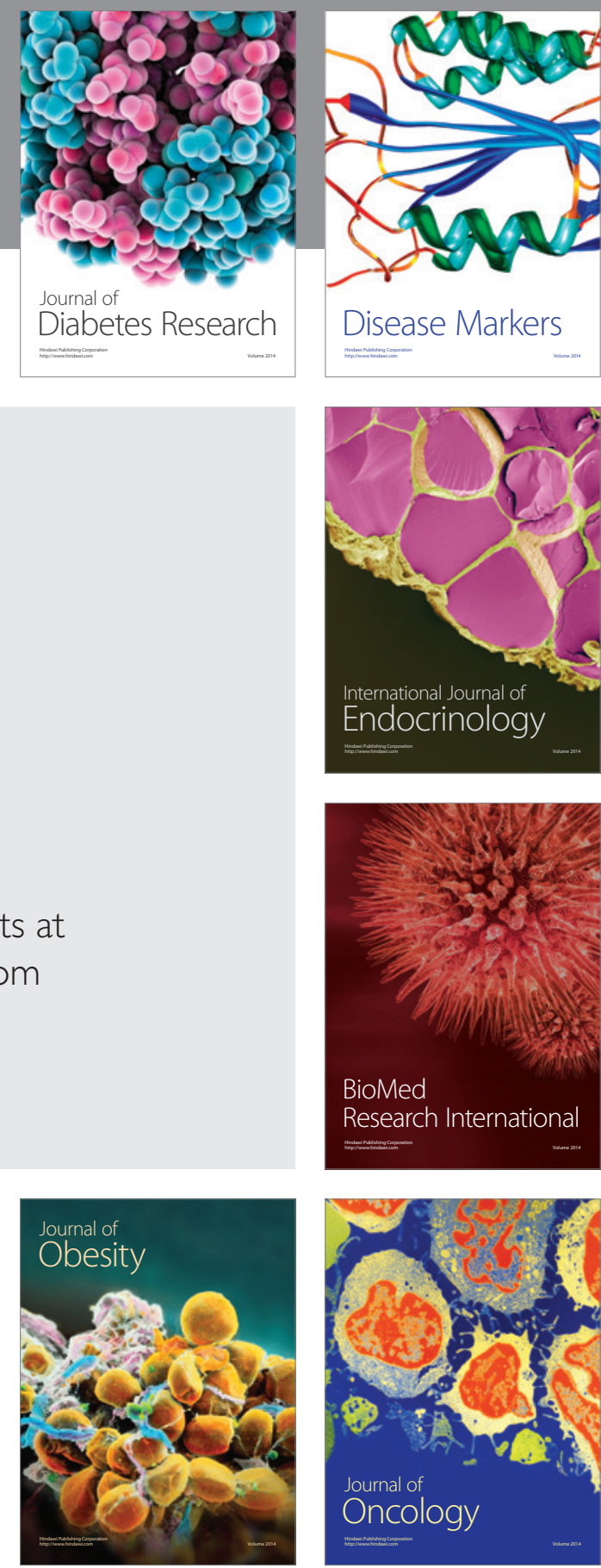

Disease Markers
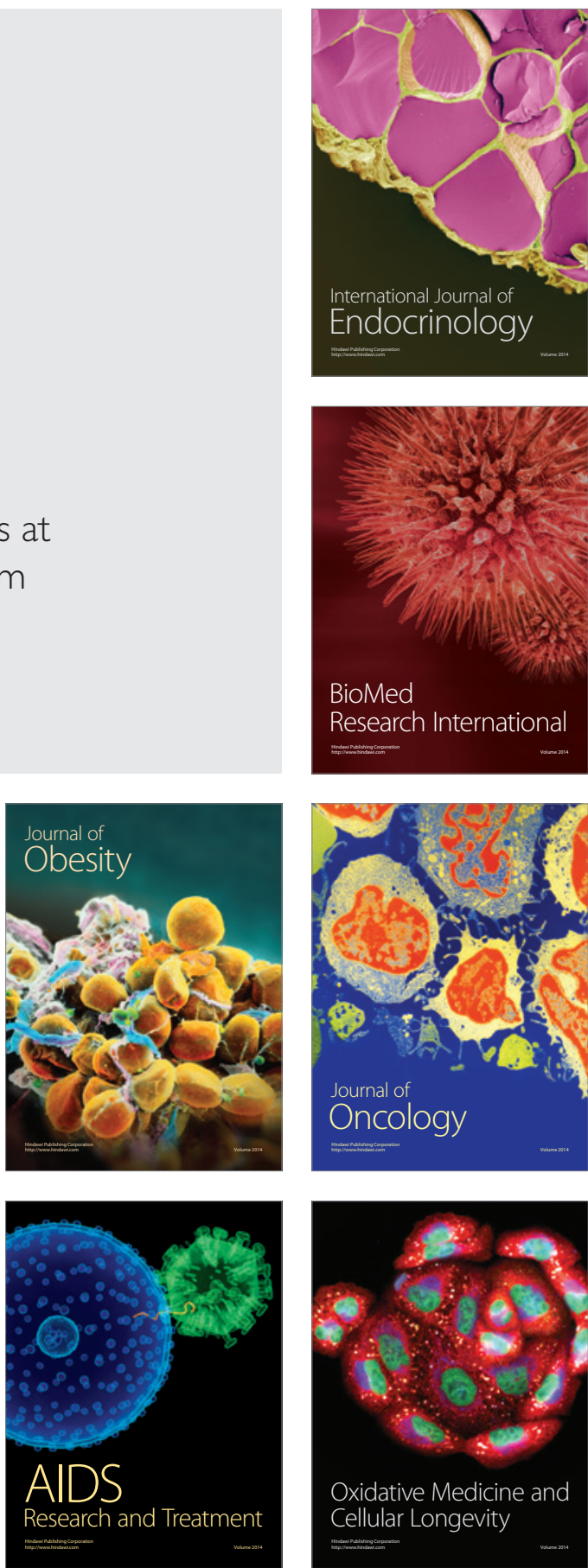